\title{
LEVANTAMENTO FLORÍSTICO DO COMPONENTE ARBUSTIVO- ARBÓREO DA VEGETAÇÃO CILIAR DE FRAGMENTO NO RIO PARAUAPEBAS
}

\author{
${ }^{1}$ Silmara Bento Silva; ${ }^{2}$ Vanderleia Conceição Sousa; ${ }^{3}$ Crissogno Mesquita Santos; \\ ${ }^{4}$ Daiane Cinque Mariano; ${ }^{5}$ Ricardo Shigueru Okumura.
1 Universidade Federal Rural da Amazônia (UFRA), Parauapebas, Pará, Brasil, silmarasilva-1991@outlook.com
${ }^{3}$ UFRA, Parauapebas, Pará, Brasil, crissogno@hotmail.com
${ }^{4}$ UFRA, Parauapebas, Pará, Brasil, daianedecinque@gmail.com \\ 2 UFRA, Parauapebas, Pará, Brasil, vanderleiacsousa@gmail.com \\ ${ }^{5}$ UFRA, Parauapebas, Pará, Brasil, ricardo_okumura@hotmail.com
}

RESUMO: As atividades relacionadas à mineração são causadoras de enormes alterações na estrutura e na dinâmica da paisagem, sendo fundamentais estudos da diversidade florística para elaboração de estratégias de conservação da biodiversidade. O objetivo do estudo foi analisar a composição florística em floresta de várzea, próximo a ambiente impactado por atividades mineradoras, localizada ao longo do rio Parauapebas. Foram instaladas 13 parcelas fixas de $10 \times 10 \mathrm{~m}\left(10 \mathrm{~m}^{2}\right)$, alocadas de forma sistemática na área de mata ciliar, ao longo da margem do rio Parauapebas, município de Parauapebas, PA. Por meio dos resultados do experimento foram identificadas 23 famílias distribuídas em 18 gêneros e 30 espécies. As famílias com maior número de espécies foram Fabaceae (11), Malvaceae (3) e Rutaceae (2). O gênero com maior riqueza em espécies foi Inga sp., com 3 espécies diferentes, respectivamente. A família Fabaceae representou 32\% das espécies coletadas, Malvaceae 10\% e Rutaceae 6\%. Das espécies amostradas, uma foi exótica, representada pelo Citrus limon (L.) Osbeck (limão-galego) e o indivíduo com maior representatividade foi Sterculia chicha A. St. -Hil., presente na maioria das parcelas. Apesar do fragmento encontrar-se ameaçado por aç̃es antrópicas, a variedade florística no local apresenta-se bastante diversificada, com espécies pioneiras, secundárias e clímax.

PALAVRAS-CHAVE: Composição florística, Flora amazônica, Riqueza.

\section{FLORISTIC SURVEY OF SHRUB-ARBOREAL COMPONENT OF CILIARY VEGETATION FRAGMENT IN PARAUAPEBAS RIVER}

ABSTRACT: The activities related to mining are causing huge changes in the structure and landscape dynamics, thus, the floristic diversity studies adopt important role in the development of tactics for biodiversity conservation. This study aimed to analyze the floristic composition in a lowland forest, located next to a degraded environment by 
mining activities, it was delimited 13 fixed plots of $10 \times 10 \mathrm{~m}\left(10 \mathrm{~m}^{2}\right)$ allocated systematically on riparian area along the river Parauapebas - PA. Were found 18 families distributed in 27 genera and 30 species. The families with the highest number of species were Fabaceae (11), Malvaceae (3) and Rutaceae (2). The genus with the highest species richness was Inga sp., With 3 different species, respectively. The Fabaceae family represented 32\% of the collected species, Malvaceae 10\% and 6\% Rutaceae. Of the species, one was exotic, represented by Citrus limon (L.) Osbeck (lemon-Galician) and the individual with the largest representation was Sterculia chicha A. St. -Hil., present in most of the plots. Despite the fragment is threatened by human activities, floristic variety on site is quite diverse, with pioneer species, secondary and climax.

KEYWORDS: Amazonian flora, Floristic composition, Wealth.

\section{LEVANTAMIENTO FLORÍSTICO DEL COMPONENTE ARBUSTIVO- ARBÓREO DE LA VEGETACIÓN CILIAR DE FRAGMENTO EN EL RÍO PARAUAPEBAS}

RESUMEN: Las actividades relacionadas con la minería son causantes de enormes cambios en la estructura y la dinámica del paisaje, siendo fundamentales estudios de la diversidad florística para la elaboración de estrategias de conservación de la biodiversidad. El objetivo del estudio fue analizar la composición florística en bosque de várzea, cerca del ambiente impactado por actividades mineras, ubicada a lo largo del río Parauapebas. Se instalaron 13 parcelas fijas de 10 × 10 m (10 m2), asignadas de forma sistemática en el área de mata ciliar, a lo largo de la margen del río Parauapebas, municipio de Parauapebas, PA. A través de los resultados del experimento se identificaron 23 familias distribuidas en 18 géneros y 30 especies. Las familias con mayor número de especies fueron Fabaceae (11), Malvaceae (3) y Rutaceae (2). El género con mayor riqueza en especies fue Inga sp., Con 3 especies diferentes, respectivamente. La familia Fabaceae representó el 32\% de las especies recolectadas, Malvaceae 10\% y Rutaceae 6\%. De las especies muestreadas, una fue exótica, representada por el Citrus limon (L.) Osbeck (limón-gallego) y el individuo con mayor representatividad fue Sterculia chicha A. St. -Hil., Presente en la mayoría de las parcelas. A pesar de que el fragmento se encuentra amenazado por acciones antrópicas, la variedad florística en el lugar se presenta bastante diversificada, con especies pioneras, secundarias y clímax.

PALABRAS CLAVES: Composición florística, Flora amazónica, Riqueza. 


\section{INTRODUÇÃO}

A floresta de várzea corresponde a segunda maior formação vegetal da região Amazônica, ocupando 75.880,8 $\mathrm{km}^{2}$, ou seja, cerca de $1,6 \%$ do bioma amazônico, com áreas inundáveis formadas por solos aluviais resultantes de contínua sedimentação de partículas suspensas nas águas dos rios (SANTOS et al., 2004).

A vegetação desenvolve-se sob inundações diárias causadas pelo fluxo das águas com frequentes adaptações ecológicas, fisiológicas e morfológicas (ALMEIDA et al., 2004), podendo influenciar na dominância de determinadas espécies da regeneração (RABELO et al., 2000).

A importância da existência de floresta ao longo de rios, ao redor de lagos, em topo de morros, córregos e reservatórios fundamenta-se no amplo aspecto de benefício que a vegetação traz ao ecossistema, exercendo função protetora no recurso natural biótico e abiótico (MELO et al., 2007).

A interação complexa do sistema é diferenciada na intensidade, no tempo e no espaço de fatores físicos (relevo e profundidade do lençol freático) e biológicos (grau de conservação, tamanho da faixa ciliar e habitat matriz), determinando-se assim a heterogeneidade florística das matas ciliares (RODRIGUES; NAVE, 2001).

Os levantamentos florísticos contribuem para a indicação dos estádios sucessionais e para melhor avaliação das influências de fatores como clima, solo e ação antrópica nas comunidades vegetais. Assim, medidas de recuperação ambiental devem ser necessariamente, precedidas de estudos de levantamento de espécies existentes em um determinado local (TRINDADE et al., 2007). Estudos florísticos em matas ciliares têm demonstrado heterogeneidade na composição e estruturação das espécies, tanto em escala geográfica quanto local (RIBEIRO-FILHO et al., 2009).

A escolha das espécies vegetais consiste numa atividade criteriosa para o sucesso de recuperação de uma área degradada, que compreende 
procedimentos e medidas necessários

à rápida estabilização do ambiente, e a progressiva instalação da utilização do solo previamente definido. O objetivo primordial deve ser a estabilidade da área em relação ao meio circunvizinho, com condições ambientais e culturais satisfatórias, produção gerenciável e potencialmente sustentável (BITAR \& VASCONCELOS, 2003).

Neste contexto, o uso de espécies nativas são as mais recomendadas por aumentar as chances de adaptações ao meio natural, além de contribuírem para conservação da biodiversidade local e regional (AMARAL, 2010).

Para estudos de levantamentos florísticos, o estabelecimento de parcelas na área que se deseja estudar é o procedimento mais comumente empregado. Usa-se a média das contagens e mensurações feitas para cada espécie em cada parcela, e supõe-se que as médias assim obtidas possam ser generalizadas para toda a fitocenose. Esses métodos permitem avaliar quantitativamente a variabilidade dos parâmetros estimados e também podem fornecer, simultaneamente, informações sobre o padrão espacial de distribuição de indivíduos em cada população (SALOMÃO et al., 2012).

Tendo em vista o conhecimento da biodiversidade e distribuição de espécies de mata ciliar nativa e exóticas na região, o objetivo do estudo foi analisar a composição florística em floresta de várzea, próximo a ambiente degradado por atividades mineradoras, localizada ao longo do rio Parauapebas.

\section{MATERIAL E MÉTODOS}

ÁREA DE ESTUDO

O estudo foi realizado em floresta de várzea com aproximadamente 140 metros de comprimento, e 200 m de largura, situado à margem do rio Parauapebas, localizada nas coordenadas geográficas 05054'20,45" latitude Sul e 49053'13,53" latitude Oeste, a $10 \mathrm{~km}$ do Assentamento Palmares Sul, pertencente ao município de Parauapebas, PA (Figura 1). 
Figura 1. Localização da área experimental no município de Parauapebas-PA.

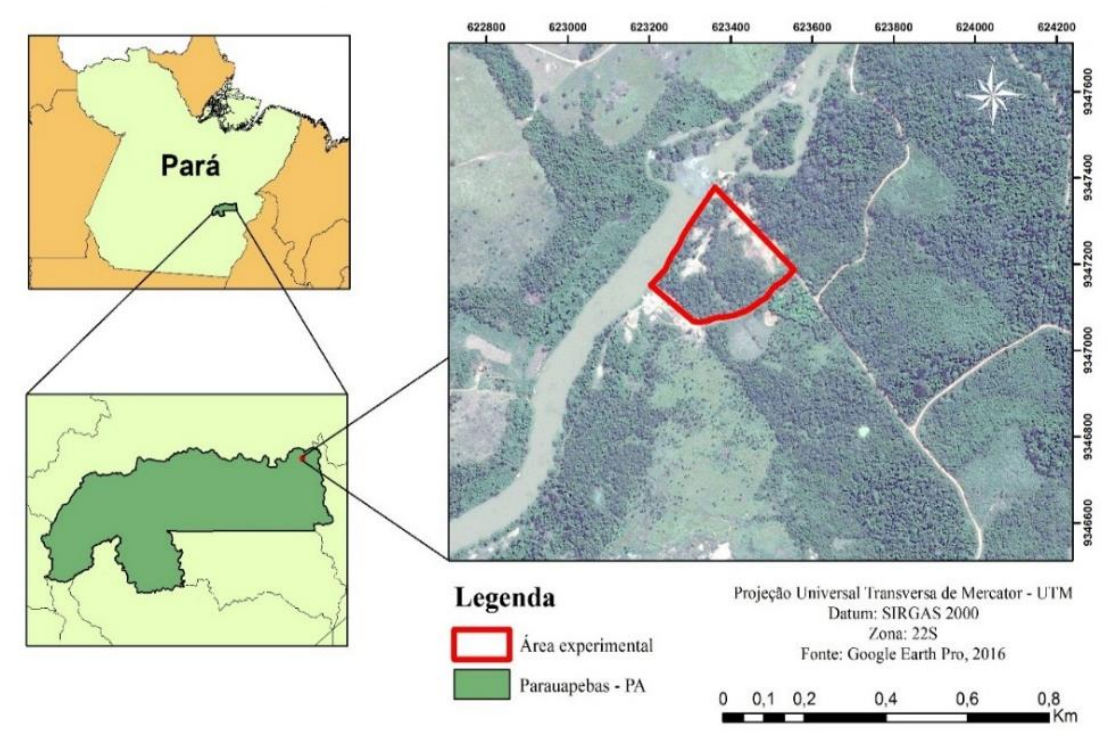

Fonte: Elaborado pelo autor.

Pela sua posição geográfica (zona tropical), e ao relevo, o município apresenta dois subtipos de clima, o de planícies e o de montanhas, em que compõem, segundo a classificação de Köeppen, o clima "Am", definido como tropical quente e úmido, com precipitação pluviométrica elevada. 0 período chuvoso ocorre notadamente de novembro a maio, e o mais seco, de junho a outubro. $\bigcirc$ índice pluviométrico anual é de $2.000 \mathrm{~mm}$ e a temperatura média anual de $26,35^{\circ} \mathrm{C}$ (SIQUEIRA et al., 2012).

O rio Parauapebas é o responsável pelo fornecimento de água para quase a totalidade do abastecimento público da cidade e, devido ao processo de ocupação humana existente nas margens observa-se a modificação da mata ciliar, a partir da degradação causada pela extração de rocha e areia para construção civil, lançamento de resíduos sólidos e efluentes às suas margens.

A área de estudo encontra-se próximo a Floresta Nacional de Carajás, que de acordo com Gumier-Costa (2009), caracteriza-se como um grande maciço de floresta ombrófila, floresta semi-caducifólia e campos rupestres rodeada por pastagens. 
A vegetação encontrada na área de estudo, compreende a de floresta secundária, com presença de muitos indivíduos pioneiros, poucas árvores em estágio clímax e secundárias tardias.

Os solos encontrados na região são classificados como Latossolos Vermelho Amarelos distróficos, de textura média à argilosa, Plintossolos, Gleissolos Húmicos distróficos e Neossolos de textura indiscriminada (FURTADO, 2014).

\section{PARCELAS, AMOSTRAGEM E COLETA} DE DADOS

As avaliações ocorreram no período de abril a maio de 2015 e, para a caracterização da composição arbórea, foram delimitados 140 m de floresta de várzea, totalizando 13 parcelas fixas de $10 \times 10 \mathrm{~m}\left(10 \mathrm{~m}^{2}\right)$, alocadas de forma sistemática no decorrer do fragmento florestal paralelo ao rio Parauapebas. Foram retirados 10 metros de bordadura no início e no fim do fragmento, conforme recomendado por Pereira (2015).

Entretanto, devido à alta degradação por atividades de mineração no entorno do rio Parauapebas, o fragmento florestal se apresentava bastante ameaçado, com uma área extremamente pequena, não excedendo a $150 \mathrm{~m}$ de comprimento e $210 \mathrm{~m}$ de largura (Figura 2).

Figura 2. Área degradada próxima ao fragmento florestal no ano de 2015.

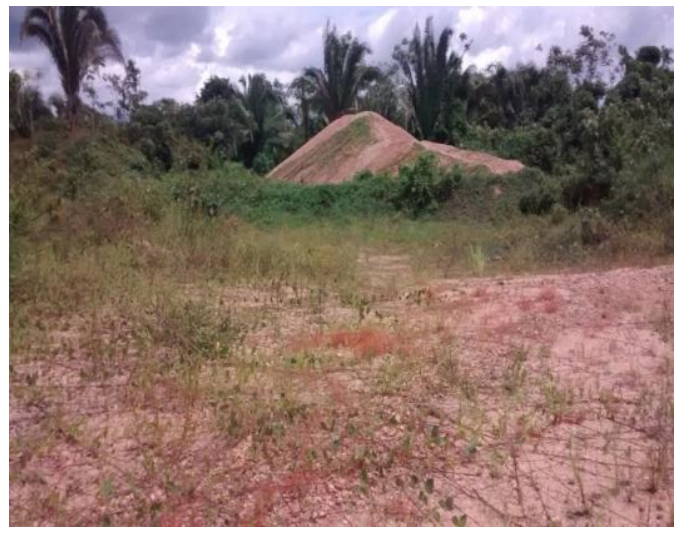

Fonte: SILVA (2015).

As parcelas foram enumeradas seguindo uma linha reta até o fim do fragmento florestal, conforme o modelo da Figura 3. 
Figura 3. Modelo de parcelas fixas em linha reta implantado no fragmento florestal.

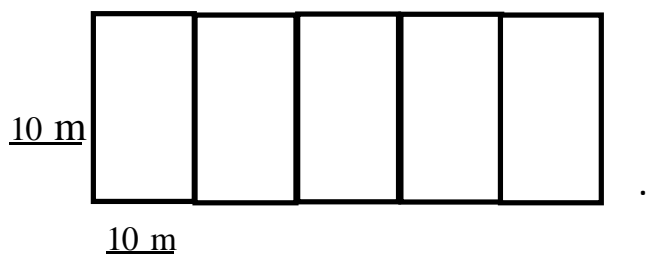

Fonte: SILVA (2016).

Em cada parcela, foram identificados e mensurados os indivíduos que apresentavam circunferência a partir de $5 \mathrm{~cm}$, preferencialmente os com flores e frutos, sem deformidades. Para tanto, utilizou-se tesoura de poda manual, por meio de escalada nas árvores ou diretamente do chão e registros fotográficos (Figura 4).

$\mathrm{Na}$ ficha de campo foram registradas informações botânicas, como características visíveis dos indivíduos arbóreos, rasteiros, época de florescimento e frutificação, além da data de coleta, e outras observações relacionadas à cada parcela (IURK, 2008).
Figura 4. Lacistema aggregatum (Berg.) Rusby localizada no fragmento florestal em que se realizou o levantamento florístico.

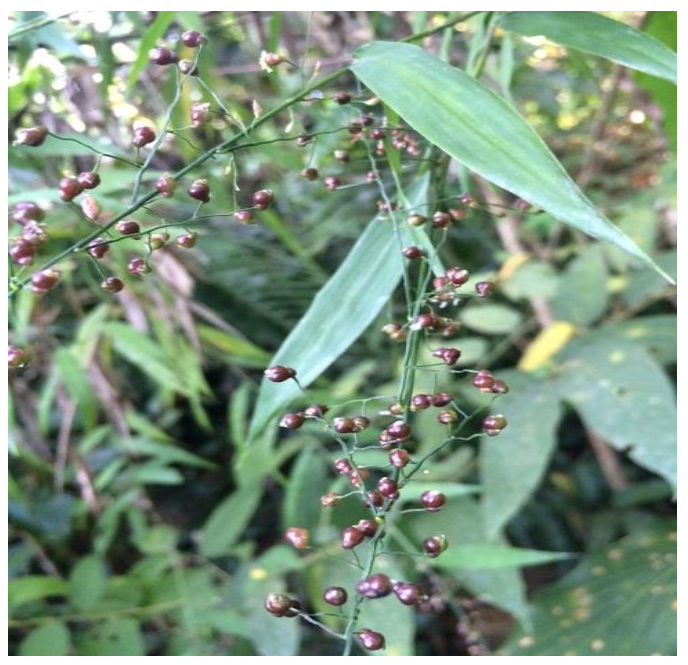

Fonte: SILVA (2015).

Cada material coletado foi numerado com o ponto e lote (ex.: Pt 01, Lt- 03), em que os pontos se caracterizavam pelas parcelas demarcadas, e o lote sendo cada vegetal recolhido dentro da parcela. As amostras foram acondicionadas em exsicatas de acordo com as recomendações de Machado e Barbosa (2010). Posteriormente, as amostras foram conduzidas para o laboratório de botânica do Parque Zoobotânico Vale em Carajás (PZV), a identificação foi realizada pelo 
identificador botânico da empresa Vale Carajás- PA, Delmo Fonseca.

Para conhecer as espécies coletadas no levantamento ao longo do rio Parauapebas, realizaram-se comparações com o herbário do Parque Zoobotânico Vale em Carajás e herbário da EMBRAPA Florestas. As informações foram obtidas por meio de pesquisa em fichários e os resultados foram registrados em ficha específica, e, posteriormente, compilados em planilhas comparativas (IURK, 2008).

\section{RESULTADOSE DISCUSSÃO}

O levantamento florístico apresentou a ocorrência de 18 famílias distribuídas em 27 gêneros e 30 espécies, que se encontram descritas na Tabela 1.

As famílias com maior número de espécies foram Fabaceae (11), Malvaceae (3) e Rutaceae (2). O gênero com maior riqueza em espécies foram Inga sp., com 3 espécies diferentes.

A elevada riqueza da família Fabaceae encontrada no presente estudo estão de acordo com os registrados por Braga et al. (2015) estudando a composição florística em floresta de várzea na Amazônia, realizado, na qual a presente família apresentou elevada abundância, com um total de 13 espécies diferentes coletadas. De acordo com Wittmann et al. (2006), Fabaceae é uma das famílias mais representativas nas florestas de várzea, da região oriental, central e ocidental da Amazônia.

De acordo com a Tabela 2, verificou que a família Fabaceae correspondeu a 32,4\% das espécies coletadas, Malvaceae 10,4\% e Rutaceae 6,2\%.

Ferreira et al. (2011) na Floresta Nacional Saracá-Taquera em Oriximiná - PA, avaliaram 179 parcelas de 250 m x 10 m, em que foram identificadas 631 espécies. A maioria das espécies apresentou baixa frequência absoluta nas parcelas, pois entre as 631 espécies, 90 (14\% do total) ocorreram em somente uma parcela, 77 (12\% do total) ocorreram em duas parcelas e 442 espécies (70\% do total) ocorreram em menos de $10 \%$ do total das parcelas. 
Tabela 1. Espécies identificadas no inventário florístico ao longo do rio Parauapebas, no ano de 2015.

\begin{tabular}{|c|c|c|}
\hline Família & Nome Científico & Nome Vulgar \\
\hline Anacardiaceae & Spondias mombin L. & Cajá \\
\hline Arecaceae & Mauritia flexuosa L. & Buriti \\
\hline Bignoniaceae & Jacaranda copaia (Aubl.) D. Don & Parapará \\
\hline Bixaceae & Bixa arborea Huber & Urucu da mata \\
\hline Burseraceae & Protium crenatum Sandwith & Breu vermelho \\
\hline Euphorbiaceae & Manihot esculenta Crantz & Mandioca \\
\hline Fabaceae & Inga sp. & Ingá \\
\hline Fabaceae & Inga laurina (Sw.) Willd. & Ingá-banana \\
\hline Fabaceae & Vatairea guianensis Aubl. & Angelim-Amargoso \\
\hline Fabaceae & $\begin{array}{l}\text { Senna macranthera (Collad.) Irwin e } \\
\text { Barn. }\end{array}$ & Fedegoso \\
\hline Fabaceae & Pterocarpus rohrii Vahl & Pau-de-sangue \\
\hline Fabaceae & Mimosa asperata $\mathrm{L}$. & Juquiri \\
\hline Fabaceae & $\begin{array}{l}\text { Hydrochorea corymbosa (Rich.) Barn. e } \\
\text { Grimes }\end{array}$ & Paricá-do-Igapó \\
\hline Fabaceae & Inga edulis Mart. & Ingá-cipó \\
\hline Fabaceae & Bauhinia longipedicellata Ducke & Rosa-da-montanha \\
\hline Fabaceae & $\begin{array}{l}\text { Schizolobium amazonicum (Huber) } \\
\text { Ducke }\end{array}$ & Paricá \\
\hline Hypericaceae & Vismia latifolia (Aubl.) Choisy & Lacre marrom/vermelho \\
\hline Lacistemataceae & Lacistema aggregatum (Berg.) Rusby & Mata-calado \\
\hline Lecythidaceae & Bertholletia excelsa Humb. e Bonpl. & Castanha-do-Pará \\
\hline Malvaceae & Ceiba pentandra (L.) Gaertn. & Sumaúma \\
\hline Malvaceae & Sterculia chicha A. St. -Hil. & Axixá \\
\hline Malvaceae & Theobroma speciosum (Willd.) Spreng. & Cacauí \\
\hline Rubiaceae & Palicourea marcgravii A. St. -Hil. & Erva-de-rato \\
\hline Rutaceae & Citrus limon (L.) Osbeck & Limão- galego \\
\hline Rutaceae & Metrodorea flavida K. Krause & Pirarara \\
\hline Salicaceae & Laetia procera (Poepp.) Eichler & Pau jacaré \\
\hline Sapindaceae & Cupania vernalis Cambess. & Camboatá \\
\hline Sapotaceae & Pouteria ramiflora (Mart.) Radlk. & Massaranduba \\
\hline Solanaceae & Solanum crinitum Lam. & Fruto-do-lobo \\
\hline Strelitziaceae & $\begin{array}{l}\text { Phenakospermum guyanense (Rich.) } \\
\text { Miq. }\end{array}$ & Bananeira-do-mato \\
\hline
\end{tabular}

Fonte: Elaborado pelo autor.

As famílias Fabaceae e Malvaceae proporcionaram maior número de espécies no levantamento realizado, provavelmente em decorrência de algumas espécies apresentarem artifícios adaptativos na estrutura radicular para fixação de nitrogênio em áreas inundáveis, por meio da associação de bactérias diazotróficas fixadoras de nitrogênio (SANTOS; JARDIM, 2006), 
influenciando no crescimento e no desenvolvimento vegetativo, o que consiste na preponderância numérica de espécies de uma mesma família, característica comum em florestas tropicais (MAUÉS, 2011).

Tabela 2. Famílias, Número de espécies ( $N^{\circ} \mathrm{sp}$ ), Frequência, identificadas no inventário florístico em um trecho de floresta de várzea do rio Parauapebas/PA, no ano de 2015.

\begin{tabular}{lcc}
\hline Família & $N^{\circ}$ sp & $F(\%)$ \\
\hline Anacardiaceae & 1 & 3,4 \\
Arecaceae & 1 & 3,4 \\
Bignoniaceae & 1 & 3,4 \\
Bixaceae & 1 & 3,4 \\
Burseraceae & 1 & 3,4 \\
Euphorbiaceae & 1 & 3,4 \\
Fabaceae & 10 & 32,4 \\
Hypericaceae & 1 & 3,4 \\
Lacistemataceae & 1 & 3,4 \\
Lecythidaceae & 1 & 3,4 \\
Malvaceae & 3 & 10,4 \\
Rubiaceae & 1 & 3,4 \\
Rutaceae & 2 & 6,2 \\
Salicaceae & 1 & 3,4 \\
Sapindaceae & 1 & 3,4 \\
Sapotaceae & 1 & 3,4 \\
Solanaceae & 1 & 3,4 \\
Strelitziaceae & 1 & 3,4 \\
\hline
\end{tabular}

Fonte: Elaborado pelo autor.

Brito et al. (2008) verificaram que as inundações sazonais do solo influenciaram na germinação, no estabelecimento e na dominância das espécies arbóreas, além da posição topográfica e da umidade na formação de grupos florísticos. De acordo com Gama et al. (2005), estudos direcionados para a distribuição espacial de espécies lenhosas auxiliam na compreensão da ocorrência e regeneração, possibilitando subsídios na criação de estratégias de manejo sustentável e ecológico.

As espécies identificadas, em sua maioria, encontram-se na região amazônica, localizadas principalmente no interior do fragmento florestal, como: Bertholletia excelsa_Humb. e Bonpl. (Castanha-do-Pará), Ceiba 
pentandra (L.) Gaertn. (Sumaúma), Jacaranda copaia (Aubl.) D. Don (Parapará), Spondias mombin L. (Cajá), Pterocarpus rohrii Vahl (Pau-desangue) e Pouteria ramiflora (Mart.) Radlk. (Massaranduba).

Dentre as espécies localizadas nas bordas do fragmento, destaca-se Bixa arborea Huber (urucu da mata), Lacistema aggregatum (Berg.) Rusby (mata-calado), Vismia latifolia (Aubl.) Choisy (lacre marrom/vermelho), Mauritia flexuosa L. (buriti), Manihot esculenta Crantz (Mandioca) e Citrus limon (L.) Osbeck (limão-galego) de caráter exótico invasor.

Salomão et al. (2012), estudando a Floresta Nacional Saracá-Taquera, no município de Oriximiná - PA, identificaram as espécies Sapotaceae (97 espécies), Mimosaceae (56), Chrysobalanaceae (46), Lauraceae (45), Fabaceae (42), Annonaceae (39), Myrtaceae (37), Moraceae (35), Lecythidaceae (33), Burseraceae e Caesalpiniaceae (31 espécies cada); apenas, considerando Leguminosae (sensu lato), esta seria a família com maior riqueza: 129 espécies.

Das espécies amostradas apenas o Citrus limon (L.) Osbeck (limão-galego) possui caráter exótico, provavelmente, foi introduzido no fragmento florestal por meio do fluxo de pessoas que frequentam a área para atividades de lazer, e/ou também por propagação zoocórica e anemocórica das sementes provenientes das áreas de cultivo de moradias circunvizinhas (ALMEIDA, 2004). Vale salientar a presença da espécie Citrus limon (L.) Osbeck em ambientes de Áreas de Tensão Ecológica (Floresta Ombrófila-Floresta Estacional), Floresta Estacional Semidecidual e Formações Pioneiras de Influência Marinha (Restingas) (BIONDI, 2008).

As espécies com maior frequência amostradas em floresta de várzea estão apresentadas na Figura 4. A partir dos resultados observou dominância de três indivíduos: 1) Sterculia chicha A. St. -Hil. abrangendo 43\% da área, caracterizada por ser uma espécie de caráter arbóreo, de 
crescimento rápido, pioneira, nativa da região de Meio-Norte do Brasil (DIAS, 2004); 2) Lacistema aggregatum (Berg.) Rusby, compreendendo 29\% das plantas avaliadas, caracteriza-se pela sua origem tóxica, crescimento rápido e nativa da região amazônica; 3) Bixa arborea Huber com 28\% de indivíduos, a espécie caracteriza-se pela baixa estatura, copa baixa e densa, ocorre naturalmente na floresta pluvial da região Amazônica até a Bahia, geralmente ao longo dos rios (CORADIN et al., 2011).

Figura 5. Frequência de espécies amostradas em floresta de várzea em um trecho do rio Parauapebas-PA.

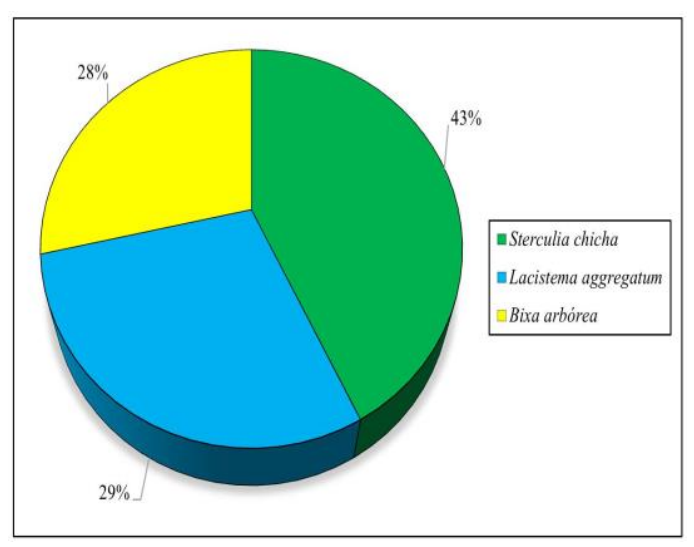

Fonte: Elaborado pelo autor.

Apesar do fragmento estar ameaçado por ações antrópicas, a variedade no local é satisfatória, apresentando espécies pioneiras, secundárias e clímax, isso ocorre devido a várzea ser formada por terras baixas e planas que margeiam os rios, além disso, por conseguinte, apresentam solos com maior fertilidade devido ao depósito de sedimentos (RODRIGUES et al., 2010).

A área de várzea no entorno do rio Parauapebas, encontra-se diretamente ameaçada pela ação antrópica acrescida das atividades de mineração e lazer (HOMMA et al., 2014), contudo abrigam espécies nativas de médio à grande porte, resistentes a certos tipos de perturbações. De acordo com Andrade et al. (2008), nas várzeas, o tipo e o tamanho do distúrbio determina as rotas para estrutura florestal futura, nesse sentido práticas de manejo como: isolamento da área, enriquecimento da floresta por meio de espécies nativas, eliminação dos agentes de degradação existentes no local, as retiradas das pilhas de seixos, conservação do solo e acima de tudo a conscientização ambiental 
direcionadas, principalmente, para os moradores vizinhos e banhistas que frequentam a localidade devem ser adotadas, para que a área estudada possa se restabelecer novamente.

\section{CONCLUSÃO}

A floresta de várzea no entorno do rio Parauapebas, apesar da ação antrópica por atividade de lazer e mineração, ainda apresenta indivíduos florestais nativos típicos. A diversidade florística é alta para espécies arbóreas, destacando-se a família Fabaceae com $32 \%$ de predominância em todo o fragmento florestal.

Espécies exóticas foram encontradas pelo fato da área de estudo, encontrar-se nas proximidades de propriedades rurais e ser bastante frequentada por pessoas para lazer.

Para complementação dos resultados apresentados sugerem a necessidade de pesquisas como: avaliação dos impactos existentes na área degradada, estrutura fitossociológica, métodos de conservação do solo, qualidade da água e levantamento da fauna local, assim, proporcionando a implantação de técnicas de recuperação e conservação nestes ambientes, minimizando os impactos causados pela ação antrópica nas áreas de preservação permanente do município de Parauapebas, PA.

\section{REFERÊNCIAS}

ALMEIDA, A. F. Análise etnológica da floresta de várzea da Ilha de Sorocaba, Ananindeua, Pará, Brasil. 2010. 62 f. Dissertação (Pós-graduação), Universidade Federal do Pará, Belém, 2010.

ALMEIDA, S. M.; AMARAL, D. D.; SILVA, A. S. L. Análise florística e estrutura de florestas de várzea no estuário amazônico. Acta Amazonica, v.34, n.4, p.513-524, 2004.

AMARAL, L. A. Recuperação De Áreas Degradadas Via Semeadura Direta De Espécies Florestais Nativas, SE. 2010. 52 f. Dissertação (Graduação em Engenharia Florestal), Universidade Federal de Sergipe, Sergipe, 2010.

ANDRADE, T. M.; ASSIS, R. L.; WITTMANN, F.; SCHÖNGART, J.; PIEDADE, M. T. F. Padrões de regeneração em clareiras de origem antrópica na várzea da RSD Mamirauá, Amazônia Central. Uakari, Mamirauá, v. 4, n. 2, p. 19-32, 2008. 
BATISTA, F. Diagnostico florístico e mapeamento de locais críticos em áreas de preservação permanente em função do índice de diversidade de Shannon. 2012. 95 f. Dissertação (PósGraduação em Produção Vegetal), Universidade do Estado de Santa Catarina, Lages, 2012.

BIONDI, D.; PEDROSA-MACEDO, J. H. Plantas invasoras encontradas na área urbana de Curitiba -PR. Floresta, Curitiba, v. 38, n. 1, 2008.

BITAR, O. Y.; VASCONCELOS, M. M. T. Recuperação de Áreas degradas. In: MINERAÇÃO \& MUNICÍPIO: Bases Para Planejamento E Gestão Dos Recursos Minerais. São Paulo: IPT, 2003. p.111155.

BRAGA, E. O.; SILVA, J. A. F.; PANTOJA, M. V.; GONÇALVES, M. A. Florística, estrutura fitossociológica e formas de vida do estrato inferior em uma floresta de várzea Amazônica. Biota Amazônia, Macapá, v. 5, n. 3, p. 59-65, 2015.

BRITO, E. R.; MARTINS, S. V.; OLIVEIRAFILHO, A. T. Estrutura fitossociológica de um fragmento natural de floresta inundável em área de campo sujo, Lagoa da Confusão, Tocantins, Acta Amazonica, Manaus. v.38, n.3, p.379386, 2008.

CARDOSO-LEITE, E.; COVRE, T. B.; OMETTO, R. G.; CAVALCANTI, D. C.; PAGANI, M. I. Fitossociologia e caracterização sucessional de um fragmento de Mata Ciliar, em Rio Claro, SP, como subsídio à recuperação da área. Revista do Instituto Florestal, São Paulo, v. 16, n. 1, p. 31-41, 2004.

CORADIN, L.; SIMINSKI, A.; REIS, A. Espécies nativas da Floresta Brasileira de valor econômico atual ou potencial: Plantas para o futuro. 2. ed. Brasília, DF: Instituto do Meio Ambiente e dos Recursos Naturais Renováveis, 2011. 816 p.

DIAS, R. R. Zoneamento ecológicoeconômico: Estudo de flora e fauna Norte do Estado do Tocantins. 1. ed. Tocantins: Diretoria de Zoneamento Ecológico-Econômico - DZE, 2004.

FERREIRA, L.V.; SALOMÃO, R.P.; MATOS, D.C.L.; PEREIRA, J.L.G. Similaridade de espécies arbóreas em função da distância em uma floresta ombrófila na Floresta Nacional de Saracá-Taquera, Pará. Boletim do Museu Paraense Emílio Goeldi. Ciências Naturais, v. 6, p.295-306, 2011.

FURTADO, A. M. M.; PONTE, F. C. Ocupação e impactos decorrentes da expansão urbana da cidade de Parauapebas, estado do Pará. Revista do Instituto Histórico e Geográfico do Pará (IHGP), Belém, v. 1, n. 1, p. 123-134, 2014.

GAMA, J. R. V.; BENTES-GAMA, M. M.; SCOLFORO, J. R. S. Manejo sustentado para floresta de várzea na Amazônia oriental. Revista Árvore, Viçosa, v.29, n.5, p.719-729, 2005.

GAMA, J. R. V.; BOTELHO, S. A.; BENTES-GAMA, M. M.; SCOLFORO, J. R. S. Estrutura e potencial futuro de 
utilização da regeneração natural de floresta de várzea alta no município de Afuá, estado do Pará. Ciência Florestal, Santa Maria, v.13, n.2, p.71-82, 2003.

GUMIER-COSTA, F. \& SPERBER, C. F. Atropelamentos de vertebrados na Floresta Nacional de Carajás, Pará, Brasil. Acta Amazonica, Carajás, v. 39, n. 2, p. 459-466, 2009.

HOMMA, A.K.O.; MENEZES, A.J.E.A.; MAUÉS, M.M. Castanheira-do-pará: Os desafios do extrativismo para plantios agrícolas. Boletim do Museu Paraense Emílio Goeldi. Ciências Naturais, v. 9, p.293-306, 2014.

IURK, M. C. Levantamento Florístico de um Fragmento de Floresta Ombrofila Mista Aluvial do Rio Iguaçu, Município de Palmeira -PR. 2008. $114 \mathrm{f}$. Dissertação (Mestrado), Universidade Federal do Paraná, Paraná, 2008.

IVANAUSKAS, N. M.; MONTEIRO, R.; RODRIGUES, R. R. Estrutura de um trecho de floresta Amazônica na bacia do alto rio Xingu. Acta Amazonica, Manaus, v. 34, n.2, p. 275-299, 2004.

KUNZ S. H.; IVANAUSKAS N. M.; MARTINS S. V.; SILVA E.; STEFANELLO D. Análise da similaridade florística entre florestas do Alto Rio Xingu, da Bacia Amazônica e do Planalto Central. Revista Brasil Botânica, Viçosa, v. 32, n.4, p.725-736, 2009.

MACHADO, S. R.; BARBOSA, S. B. Herbário Botucatu: Manual de procedimentos. 1. ed. Botucatu, SP: Instituto Biociências, 2010. 18 p.
MAUÉS, B. A. R.; JARDIM, M. A. G.; BATISTA, F. J.; MEDEIROS, T. D. S.; QUARESMA, A. C. Composição florística e estrutura do estrato inferior da Floresta de várzea na área de proteção ambiental Ilha do Combu, município de Belém, estado do Pará. Revista Árvore, Viçosa, v.35, n.3, Edição Especial, p.669-677, 2011.

MELO, A. C. G.; MIRANDA, D. L. C.; DURIGAN, G. Cobertura de copas como indicador de desenvolvimento estrutural de reflorestamentos de restauração de matas ciliares do Médio do Paranapanema. Revista Árvore, São Paulo, v.31, n.2, p.321-328, 2007.

OLIVEIRA, A. N.; AMARAL, I. L. Aspectos florísticos, fitossociológicos e ecológicos de um sub-bosque de terra firme na Amazônia Central, Amazonas, Brasil. Acta Amazonica, Manaus, v.35, n.1, p.1-16, 2005.

OLIVEIRA, A. N.; AMARAL, I. L. Florística e fitossociologia de uma floresta de vertente na Amazônia Central, Amazonas, Brasil. Acta Amazonica, v.34, n.4 p. 21-34, 2004.

PEREIRA， F. C.; LENZA， E.; MARACAHIPES-SANTOS, L.; MEWS, $H$. A.; GOMES, L.; LIMA, S. L.; SANTOS, K. S. M. Comparação dos métodos de parcelas e pontos-quadrantes para descrever uma comunidade lenhosa de Cerrado Típico. Biotemas, Nova Xavantina-MT, v.28, n.2, p. 61-72, 2015.

RABELO, F. G. et al. Regeneração natural de florestas esturianas na região do rio Amazonas- Amapá- 
Brasil. Revista de Ciências Agrárias, v.34, n.4, p.129-137, 2000.

RIBEIRO-FILHO, A. A. Composição florística da floresta ciliar do rio Mandassaia, Parque Nacional da Chapada Diamantina, Bahia, Brasil. Revista Rodriguésia, Rio de Janeiro, $v$. 60, n. 2, p. 265-276, 2009.

ROCHA, V. C. N.; ALVES, M. N. C. B. Q.; MOURA, L.; SOUZA, A. P. S.; ROCHA, M. B. Levantamento florístico de floresta tropical secundária na área do parque Ambiental do Utinga, BelémPa. Enciclopédia Biosfera, Goiânia, v.8, n. 14, p.12-99, 2012.

RODRIGUES, R. R.; GANDOLFI, S. Conceitos, tendências e ações para a recuperação de florestas ciliares. In: RODRIGUES, R. R.; LEITÃO, H. DE F. (eds.). Matas Ciliares: conservação e recuperação. $2^{\circ}$ ed. São Paulo: Editora da Universidade de São Paulo: Fapesp, 2001. p. 235-247.

RODRIGUES, R. R.; LEITÃO-FILHO, H. F. Matas ciliares: conservação e recuperação. 2. ed. São Paulo: Edusp, 2000. 320 p.

RODRIGUES, R. R.; NAVE, A. Heterogeneidade florística das matas ciliares. In: RODRIGUES, R. R.; LEITÃO FILHO, H. de F. (Org.). Matas ciliares: conservação e recuperação. São Paulo, Edusp: FAPESP, 2001. p. 45-71.

RODRIGUES, V. H. P.; LOPES, S. F.; ARAUJO, G. M. E; SCHIAVINI, I. Composição, estrutura e aspectos ecológicos da floresta ciliar do rio
Araguari no Triângulo Mineiro. Hoehnea, São Paulo, v. 37, n. 1, p. 87 105, 2010.

SALOMÃO, R.P.; SANTANA, A.C.; BRIENZA JÚNIOR, S.; GOMES, V.H.F. Análise fitossociológica de floresta ombrófila densa e determinação de espécies-chave para recuperação de área degradada através da adequação do índice de valor de importância. Boletim do Museu Paraense Emílio Goeldi. Ciências Naturais, v.7, p.57-102, 2012.

SANTOS, G. C.; JARDIM, M. A. G. Florística e estrutura do estrato arbóreo de uma floresta de várzea no município de Santa Bárbara do Pará, Estado do Pará, Brasil. Acta Amazonica, v. 36, n. 4, p.437-446, 2006.

SANTOS, S. R. M.; MIRANDA, I. S.; TOURINHO, M. M. Análise florística e estrutural de sistemas agroflorestais das várzeas do rio Juba, Cametá, Pará. Acta Amazonica, v.34, n.2, p.251-263, 2004.

SIQUEIRA, G. W.; APRILE, F.; MIGUÉIS A. M. Diagnóstico da qualidade da água do rio Parauapebas (Pará - Brasil). Acta Amazônica, Belém, v. 42, p. 413-422, 2012.

TRINDADE M. J. S.; ANDRADE C. R.; SOUZA L. A. L. Florística e Fitossociologia da Reserva do Utinga, Belém, Pará, Brasil. Revista Brasileira de Biociências, Porto Alegre, v. 5, n.2, p. 234-236, 2007. 
VIEIRA, E. G.; REZENDE E. N. Mineração de areia e meio ambiente: é possível harmonizar? Revista do Direito Público, Londrina, v.10, n.3, p.181-212, 2015.

WITTMANN, F.; SCHÖNGART, J.; MONTERO, J. C.; MOTZER, T.; JUNK, W. J.; PIEDADE, M. T. F.; QUEIROZ, H. L.; WORBES, M. Trees species composition and diversity gradients in white-water forests across the Amazon Basin. Journal of Biogeography, v.33, n.8, p.1334-1347, 2006. 